\title{
ANALISIS PENDAPATAN DAN RC PADA AGROINDUSTRI GULA SEMUT (Studi Kasus di Desa Pegadingan Kecamatan Cipari Kabupaten Cilacap)
}

\author{
ANALISYS OF NET INCOME AND RC OF THE AGROINDUSTRY OF COCONUT \\ SUGAR \\ (Case study in Pegadingan Village, Cipari District, Cilacap Regency)
}

\author{
ALIFA AULIA ${ }^{1 *}$, IWAN SETIAWAN ${ }^{2}$, AGUS YUNIAWAN ISYANTO ${ }^{1}$ \\ ${ }^{1}$ Fakultas Pertanian, Universitas Galuh Ciamis \\ ${ }^{2}$ Fakultas Pertanian Universitas Padjajaran \\ *E-mail: alifaaulia075@gmail.com
}

\begin{abstract}
ABSTRAK
Gula semut adalah gula merah yang berbentuk serbuk seperti sarang semut, memiliki aroma yang khas, dan berwarna kuning kecoklatan. Penelitian ini bertujuan untuk mengetahui: (1) Biaya pada agroindustri gula di Desa Pegadingan Kecamatan Cipari Kabupaten Cilacap, (2) Penerimaan pada agroindustri gula semut di Desa Pegadingan Kecamatan Cipari Kabupaten Cilacap, dan (3) Pendapatan dan R/C pada agroindustri gula semut di Desa Pegadingan Kecamatan Cipari Kabupaten Cilacap. Penelitian dilaksanakan dengan menggunakan studi kasus dengan jumlah sampel sebanyak 20 agroindustri gula semut di Desa Pegadingan, Kecamatan Cipari Kabupaten Cilacap. Hasil penelitian menunjukkan bahwa: (1) Biaya sebesar Rp 2.546.714, (2) Penerimaan sebesar Rp 2.980.000, dan (3) Pendapatan Rp 433.286 dan R/C sebesar 1,17.
\end{abstract}

Kata kunci: agroindustri, gula semut, pendapatan, R/C

\section{ABSTRACT}

Coconut sugar is brown sugar in the form of powder like an ant's nest, has a distinctive aroma, and has a brownish yellow in colour. This study aims to determine (1) Costs of the agroindustry of coconut sugar in Pegadingan Village, Cipari District, Cilacap Regency, (2) Revenue of the agroindustry of coconut sugar in Pegadingan Village, Cipari District, Cilacap Regency, and (3) Income and $R / C$ of the agroindustry of coconut sugar in Pegadingan Village, Cipari District, Cilacap Regency. The research was carried out by using a case study with a total sample of 20 coconut sugar agroindustry in Pegadingan Village, Cipari District, Cilacap Regency. The results showed that: (1) The cost was Rp $2,546,714$, (2) The revenue was $R p$ 2,980,000, and (3) the income was $R p 433,286$ and the $R / C$ was 1.17 .

Keywords: $R / C$, revenue, coconut sugar, agroindustry

\section{PENDAHULUAN}

Kelapa merupakan salah satu tanaman perkebunan dari famili palmae yang setiap bagiannya dapat dimanfaatkan sehingga disebut pohon kehidupan (Khotimah, dkk., 2014). Pemanfaatan kelapa sebagai bahan baku industri terus berkembang. Produk olahan kelapa bermacam-macam, mulai dari kopra, minyak kelapa, nira kelapa hingga gula kelapa dan gula semut. 
Gula semut adalah gula kelapa berbentuk bubuk yang dapat dibuat dari nira palma, yaitu suatu larutan gula cetak palmae yang telah dilebur kembali dengan penambahan air pada konsentrasi tertentu. Disebut gula semut karena tampilannya yang menyerupai sarang semut.

Selama ini, produk gula kelapa yang terdapat di pasaran masih memiliki kelemahan diantaranya memiliki daya simpan yang tidak lama (sekitar 2-4 minggu), belum adanya pengemasan yang baik, serta kurang praktis dalam penyajian. Oleh karena itu, perubahan bentuk gula kelapa dari cetak menjadi butiran (gula semut) merupakan salah satu inovasi produk yang dapat membuat gula kelapa memiliki umur simpan yang lebih panjang serta memiliki kemudahan dalam penyajian dan juga cocok untuk diekspor.

Menurut data BPS Kabupaten Cilacap (2019), pada tahun 2018 Kabupaten Cilacap memiliki areal tanaman kelapa seluas 4881,33 ha, dengan jumlah produksi 170.880 ton gula kelapa di Kecamatan Cipari. Di Kecamatan Cipari terdapat desa yang menjadi sentra produksi gula semut yaitu Desa Pegadingan dengan jumlah produksi pada tahun 2018 sebanyak 430.99 ton.

Pelaksanaan kegiatan agroindustri gula semut, pengrajin tidak terlepas dari biaya produksi. Maksud dari penggunaan biaya ini adalah untuk meningkatkan nilai ekonomi dari gula cetak dan untuk meningkatkan pendapatan serta membuka lapangan pekerjaan bagi masyarakat.

\section{METODE PENELITIAN}

Jenis yang digunakan dalam penelitian ini adalah studi kasus, dengan mengambil kasus pada agroindustri gula semut di Desa Pegadingan Kecamatan Cipari Kabupaten Cilacap. Menurut Nazir (2005), studi kasus adalah penelitian tentang status subjek penelitian berkenaan dengan suatu fase spesifik atau khas dari keseluruhan personalitas.

Lokasi penelitian dipilih secara sengaja dengan menggunakan purposive sampling. Menurut Sugiono (2012), purposive sampling yaitu teknik menentukan sampel dengan pertimbangan tertentu. Agroindustri gula semut di Desa Pegadingan Kecamatan Cipari Kabupaten Cilacap sebanyak 20 unit, dan seluruhnya diambil sebagai sampel penelitian (sensus). Menurut Fatria dkk (2017), sensus melibatkan semua anggota populasi sebagai sampel. Hal ini sering dilakukan apabila jumlah populasinya relatif kecil, kurang dari 30 orang. 
Besarnya biaya, penerimaan, pendapatan dan $\mathrm{R} / \mathrm{C}$ dihitung dengan rumus sebagai berikut:

(1) Analisis Biaya

Biaya total (Total Cost) diperoleh dengan cara menjumlahkan biaya tetap total (Total Fixed Cost/TFC) dengan biaya variabel total (Total Variable Cost) dengan rumus sebagai berikut:

$\mathrm{TC}=\mathrm{TFC}+\mathrm{TVC}$

dimana:

$\mathrm{TC}=$ Total Cost (biaya total)

TFC = Total Fixed Cost (biaya tetap total)

$\mathrm{TVC}=$ Total Variable Cost (biaya variabel total)

(2) Analisis Penerimaan Penerimaan total (Total Revenue/TR) dihitung dengan rumus sebagai berikut:

$\mathrm{TR}=\mathrm{Hy} . \mathrm{Y}$

dimana:

$\mathrm{TR}=$ Total Revenue (penerimaan total)

$\mathrm{Y} \quad=$ Kuantitas (volume penjualan)

Hy = Price (harga jual)

(3) Analisis Pendapatan

Pendapatan dihitung dengan rumus sebagai berikut:

$\pi=\mathrm{TR}-\mathrm{TC}$

dimana:

$\pi \quad=$ Pendapatan

$\mathrm{TR}=$ Total Revenue $($ penerimaan total $)$

$\mathrm{TC}=$ Total Cost (biaya total)

(4) Analisis R/C Ratio
$\mathrm{R} / \mathrm{C}$ dihitung dengan rumus sebagai berikut:

$\mathrm{R} / \mathrm{C}=\frac{T R}{T C}$

dimana:

$\mathrm{R} / \mathrm{C}=\mathrm{Rasio}$

$\mathrm{TR}=$ Total Revenue (penerimaan total)

$\mathrm{TC}=$ Total Cost (biaya total)

Dengan ketentuan sebagai berikut:

$\mathrm{R} / \mathrm{C}>1=$ menguntungkan .

$\mathrm{R} / \mathrm{C}=1=$ impas

$\mathrm{R} / \mathrm{C}<1=$ rugi

\section{HASIL DAN PEMBAHASAN}

Karakteristik Responden

Tingkat pendidikan responden tergolong rendah dimana mayoritas berpendidikan sekolah dasar (SD). Sebagian besar responden (19 orang) memiliki pengalaman berusaha gula semut di atas 10 tahun.

Secara keseluruhan usaha agroindustri gula semut kelapa yang dijalankan responden merupakan pekerjaan utama. Responden dalam penelitian ini semuanya sudah menikah, dengan jumlah 1 sampai 4 anggota keluarga sebanyak 12 orang dan 5 sampai 8 orang sebanyak 8 orang. Hal ini menunjukan bahwa sebagian besar responden memiliki 2 anak. 


\section{Analisis Usaha}

\section{(1) Analisis Biaya}

Hasil penelitian menunjukkan bahwa rata-rata biaya total sebesar $\mathrm{Rp} 2.546 .676$ yang terdiri atas biaya tetap sebesar $\mathrm{Rp}$ $43.850(1,722 \%)$ dan biaya variabel sebesar Rp 2.502.826 (98,278\%) sebagaimana terlihat pada Tabel 1 .

Tabel 1. Analisis Biaya

\begin{tabular}{|c|c|c|c|}
\hline No & Uraian & $\begin{array}{c}\text { Jumlah } \\
\text { (Rp) }\end{array}$ & $\%$ \\
\hline \multirow[t]{5}{*}{1} & Biaya Tetap & & \\
\hline & - Penyusutan Alat & 27.823 & 1,093 \\
\hline & - Bunga Modal Tetap & 11 & 0,0004 \\
\hline & $-\mathrm{PBB}$ & 16.017 & 0,629 \\
\hline & Jumlah biaya tetap & 43.850 & 1,722 \\
\hline \multirow[t]{9}{*}{2} & $\begin{array}{l}\text { Biaya Variabel } \\
\text { a. Input }\end{array}$ & & \\
\hline & - Nira & 882.000 & 34,633 \\
\hline & - Kayu bakar & 648.000 & 25,445 \\
\hline & - Plastik & 12.000 & 0,471 \\
\hline & - Rapia & 200 & 0,008 \\
\hline & b. Tenaga kerja & 960.000 & 37,696 \\
\hline & $\begin{array}{l}\text { c. Bunga Modal } \\
\text { Variabel }\end{array}$ & 626 & 0,025 \\
\hline & $\begin{array}{l}\text { Jumlah biaya } \\
\text { variabel }\end{array}$ & $\begin{array}{r}2.502 .82 \\
6 \\
\end{array}$ & 98,278 \\
\hline & Jumlah Biaya Total & $\begin{array}{c}2.546 .67 \\
6 \\
\end{array}$ & 100,00 \\
\hline
\end{tabular}

Sumber: Analisis Data Primer, 2020

\section{(2) Analisis Penerimaan}

Rata-rata produksi gula semut sebanyak 149 kilogram dengan harga jual Rp 20.000 per kilogram, sehingga penerimaan sebesar Rp 2.980.000.

Setiap anggota kelompok memproduksi jumlah yang berbeda, dalam rentang 6 sampai 10 kilogram gula semut dalam satu kali proses produksi. Penerimaan paling sedikit adalah untuk anggota yang hanya memproduksi 6 kilogram, yaitu Rp120.000, dan penerimaan yang paling banyak diperoleh untuk anggota kelompok yang memproduksi sampai dengan 10 kilogram gula semut, yaitu Rp 200.000.

\section{(3) Analisis Pendapatan dan R/C}

Pendapatan dan R/C pada agroindustri gula kelapa di Desa Pegadingan dapat dilihat pada Tabel 2.

Tabel 2. Analisis Pendapatan dan R/C

\begin{tabular}{clcr}
\hline No & \multicolumn{1}{c}{ Uraian } & Satuan & Jumlah \\
\hline 1 & Produksi & Kilogram & 149 \\
2 & Harga & Rp/Kilogram & 20.000 \\
3 & Penerimaan & $\mathrm{Rp}$ & 2.980 .000 \\
4 & Biaya Produksi & $\mathrm{Rp}$ & 2.546 .676 \\
5 & Pendapatan & $\mathrm{Rp}$ & 433.324 \\
6 & RC Ratio & & 1.17 \\
\hline \multicolumn{4}{l}{ Sumber: Analisis Data Primer, 2020 }
\end{tabular}

Tabel 2 menunjukkan pendapatan agroindustri gula semut sebesar Rp 433.324 dengan R/C sebesar 1,17 yang menunjukkan bahwa agroindustri gula semut ini menguntungkan dan layak untuk diusahakan.

\section{KESIMPULAN DAN SARAN}

\section{Kesimpulan}

1. Besarnya biaya pada agroindustri gula semut dalam satu kali proses produksi di Desa Pegadingan Kecamatan Cipari Kabupaten Cilacap adalah sebesar Rp 2.546.676.

2. Besarnya penerimaan pada agroindustri gula semut dalam satu kali proses 
produksi di Desa Pegadingan

Kecamatan Cipari Kabupaten Cilacap adalah sebesar Rp 2.980.000.

3. Besarnya pendapatan pada agroindustri gula semut dalam satu kali proses produksi di Desa Pegadingan Kecamatan Cipari Kabupaten Cilacap sebesar Rp 433.324 dan R/C sebesar 1,17 .

\section{Saran}

1. Perajin gula semut diharapkan untuk tetap memproduksi gula semut, karena usaha tersebut mampu memberikan keuntungan bagi perajin.

2. Masih dibutuhkan pembinaan untuk meningkatkan modal usaha bagi perajin gula semut, sehingga perajin dapat mandiri tidak bergantung kepada kelompok tani dan perajin bisa menentukan harga jual sendiri.

\section{DAFTAR PUSTAKA}

BPS Kabupaten Cilacap. 2019. Kabupaten Cilacap Dalam Angka 2019. Cilacap. Fatria, M. A., Jahrizal, \& Pailis, E. A. 2017. Strategi Pengembangan Industri Rumah Tangga di Kota Pekanbaru (Studi Kasus Usaha Jamur Crispy Industri Pengolahan Jamur Tiram.JOM Fekon, 4(1), 283297.

Khotimah, S., A. Kusmiati dan T. Agustina. 2014. Analisis Pendapatan Pengrajin Gula Kelapa dan Kontribusinya terhadap Pendapatan Keluarga di Desa Lojejer Kecamatan Wuluhan Kabupaten Jember.JSEP. 7 (2): 45-54.

Nazir. 2005. Metode Penelitian. Jakarta. Ghalia Indonesia.

Sugiyono. 2012. Metode Penelitian Kuantitatif, Kualitatif, dan $R \& D$. Bandung. Alfabeta. 